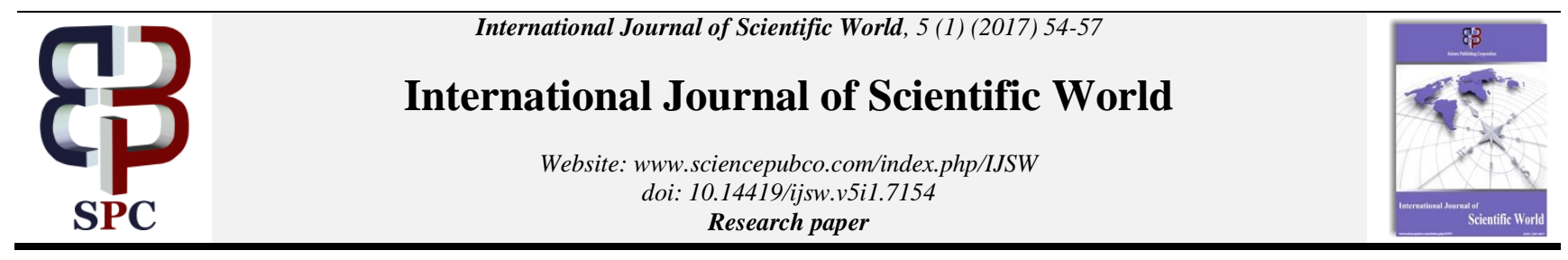

\title{
Molecular epidemiology of staphylococcus aureus isolated from the patients, personnel and hospital environments in Sanandaj (Iran)
}

\author{
Hadi Mohammadi Talvar ${ }^{1}$, Rashid Ramazanzadeh ${ }^{2 *}$, Mahdi Mirzaii ${ }^{3}$, Seyed Sajjad Hasheminasab ${ }^{4}$ \\ ${ }^{1}$ Islamic Azad University, Science and Research Campus, Kurdistan branch, Sanandaj, Iran \\ ${ }^{2}$ Cellular \& Molecular Research Center, Kurdistan University of Medical Sciences, Sanandaj- Iran \\ ${ }^{3}$ Faculty of Medicine, Shahroud University of Medical Sciences, Shahroud, Iran \\ ${ }^{4}$ Veterinary parasitologist, Damdaran Taavoni, Moalem sq,Molavi st, Dehgolan,Iran \\ *Corresponding authorE-mail: rashid@muk.ac.ir
}

\begin{abstract}
The aim of this study was to determine the prevalence and characteristics of methicillin-resistant Staphylococcus aureus (MRSA) isolates from the patients, personnel and environments of a hospital in Sanandaj. During this study, 30 MRSA isolates were collected and analyzed with using spa typing method. Out of the $30 \mathrm{~S}$. aureus isolates, 28 (93.33\%) was methicillin resistant (MRSA), 16 spa types (t030, $\mathrm{t} 711, \mathrm{t} 002, \mathrm{t} 1556, \mathrm{t} 325, \mathrm{t} 267, \mathrm{t} 1358, \mathrm{t} 230, \mathrm{t} 2422, \mathrm{t} 969, \mathrm{t} 1814, \mathrm{t} 037, \mathrm{t} 300, \mathrm{t} 044, \mathrm{t} 180$, and $\mathrm{t} 5598$ ) were found in different wards of the hospital. The most frequent were t030 (17.2\%), t711 (13.7\%). Our data demonstrated that the overall, resistances to erythromycin, gentamycin, and ciprofloxacin, were most frequent $(87.5,81.25$, and 62.5 respectively).
\end{abstract}

Keywords: Methicillin-Resistant Staphylococcus Aureus (MRSA); Meca; Spa Typing.

\section{Introduction}

S. aureus is a major nosocomial pathogen that causes a range of diseases, including endocarditis, osteomyelitis, pneumonia, toxicshock syndrome, food poisoning, and, soft-tissue infections [1], [2].In 1961, 2 years after the introduction of methicillin, S. aureus developed methicillin-resistance due to the acquisition of the mecA gene.The mecA gene, is located on a mobile genomic island, that is called staphylococcal cassette chromosome mec (SCCmec) [3].During the last decades, diverse typing methods, have been used for monitoring S. aureus spread.PFGE has been the goldstandard method for distinguishing different MRSA strains in order to monitor their spread. However, PFGE is a technically demanding and a time-consuming method [4], [5].MLST, based on the sequence polymorphism of approx. 500-bp long fragments of seven housekeeping genes was designed to study the $S$. aureus population genetic structure. However, sequencing of several genes is time-consuming and costly [5], [6].Spa typing is a reliable tool for typing S. aureus and has become the most popular MRSA typing method.The method is based on sequencing of the polymorphic X region of the protein A gene (spa), present in nearly all $\mathrm{S}$. aureus strains. The $\mathrm{X}$ region comprises of a variable number of typically 24 bp repeats flanked by well conserved regions [68].Many studies have evaluated the usefulness of spa typing for diverse epidemiological purposes and confirmed its ease of use, speed, high discriminatory power, reproducibility and typeability, and the portability of results.Spatyping is suitable for computerized analysis, and at least two commercial software packages are currently available for spa typing. The central spa server is organized by the SeqNet.org typing network, which currently includes 45 laboratories from 25 European countries[3-5], [9], [10].In this study we investigated the molecular epidemiology of MRSA strains in different wards of the hospital with Spa typing method.

\section{Materials and methods}

\subsection{Sample collecting}

This study included $30 \mathrm{~S}$. aureus isolates collected from different hospital wards, between 2014and2015 in Kurdistan University of medical sciences. All isolates were previously identified as S. aureusby a standard microbiological procedure[11]Isolates were incubated at $37^{\circ} \mathrm{C}$ for $24 \mathrm{~h}$ on blood agar and single colonies were tested with tube and slide coagulase, catalase, DNase tests, and growth on Mannitol salt agar. To confirm the identity with the species, the nuc gene was amplified by a PCR-based method, using the primers 5'AGTTCAGCAAATGCATCACA-3',5'- ACGCAA GCC TTG ACG AAC TAA AGC-3' [12].

\subsection{PCR amplification of mecA}

DNA template was prepared purified and stored until needed at $20^{\circ} \mathrm{C}[13] . \mathrm{PCR}$ amplification of the mecA gene was performed to confirm MRSA.PCR was performed with $2 \mu$ l extracted template DNA, $2 \mu 1 \mathrm{mec}$ A Primers5'TCCAGATTACAACTTCACCAGG3',5'- CCACTTCATATCTTGTAACG -3'[14]' and $11 \mu \mathrm{L}$ of master $\operatorname{mix}\left(\right.$ polymerase Taq enzyme, $\mathrm{Mgcl}_{2}, \mathrm{dNTP}, \mathrm{SO}_{4}\left(\mathrm{NH}_{4}\right)_{2}$, TrisHCI, Tween - 20) and $10 \mu 1$ deionized water in a final volume of $25 \mu \mathrm{L}$. The thermal cycling program was as follows: initial denaturation $\left(5 \mathrm{~min}\right.$ at $\left.94^{\circ} \mathrm{C}\right)$; followed by 30 cycles of denaturation $\left(60 \mathrm{sec}\right.$ at $\left.94^{\circ} \mathrm{C}\right)$, annealing $\left(60 \mathrm{sec}\right.$ at $\left.55^{\circ} \mathrm{C}\right)$, and extension $(60 \mathrm{sec}$ at $\left.72^{\circ} \mathrm{C}\right)$; and a single extension $\left(7 \mathrm{~min}\right.$ at $\left.72^{\circ} \mathrm{C}\right)$. 


\subsection{Antimicrobial susceptibility test}

The Kirby-Bauer agar disk diffusion method was used to determine the susceptibility patterns of the $\mathrm{S}$. aureus isolates, according to the Clinical and Laboratory Standards Institute (CLSI) guidelines [14]. The antibiotics tested were as follows: ciprofloxacin, erythromycin, and Gentamicin.S. aureusATCC 33591was used as the control strain.

\subsection{Spa typing}

Spa gene typing was conducted according to the procedure described by Ridom GmbH (http://www.ridom.de).PCR was performed with $4 \mu \mathrm{L}$ extracted template DNA, $3 \mu \mathrm{L}$ Spaprimers5'TAAAGACGATCCTTCGGTGAGC -3',5'- CAGCAGTAGTGCCGTTTGCTT -3' [15], and $25 \mu \mathrm{l}$ master mix(polymerase Taq enzyme, $\mathrm{Mgcl}_{2}, \mathrm{dNTP}, \mathrm{SO}_{4}\left(\mathrm{NH}_{4}\right)_{2}$, TrisHCI, Tween - 20) and $18 \mu$ deionized water in a final volume of $50 \mu$. The thermal cycling program was as follows: initial denaturation $\left(5 \mathrm{~min}\right.$ at $\left.94^{\circ} \mathrm{C}\right)$; followed by 35 cycles of denaturation $\left(45 \mathrm{sec}\right.$ at $\left.94^{\circ} \mathrm{C}\right)$, annealing $(60$ $\mathrm{sec}$ at $\left.58^{\circ} \mathrm{C}\right)$, and extension $\left(60 \mathrm{sec}\right.$ at $\left.72^{\circ} \mathrm{C}\right)$; and a single extension $\left(10\right.$ min at $\left.72^{\circ} \mathrm{C}\right)$. Amplified PCR products were visualized by agarose gel electrophoresis in a $2 \%$ agarose gel at $100 \mathrm{~V}$ for 40 min and sequenced at Macrogen Inc. (Seoul, Korea).Data were analyzed using the Spa Server database (http://SpaServer.ridom.de).

\section{Results and discussion}

In overall, 30 strains of S. aureus have been isolated from different wards of the hospital such as Pediatric, Surgery, Emergency, Surgery, Internal ,Infection,PICU(pediatric PICU(pediatric ICU) ,Orthopedic, Cardiac, and ICU. Of the $30 \mathrm{~S}$. aureus isolates, 27 (93.33\%) were methicillin-resistant (MRSA). Looking at the frequency of resistance to antimicrobial agents of the strains (Table 1) revealed that the resistances to erythromycin, Gentamycin, and Ciprofloxacin were most frequent $(87.5,81.25$, and $62.5 \%)$ respectively. The spa types were assigned by sequencing analysis of PCR products of the spa gene (Table 2). Sixteen spa types ( $\mathrm{t} 030$, t711, t002, t1556, t325, t267, t1358, t230, t2422, t969, t1814, $\mathrm{t} 037, \mathrm{t} 300, \mathrm{t} 044, \mathrm{t} 180$ and $\mathrm{t} 5598$ ) were found different wards of the hospitals. The most frequent were t030 (17.2\%), t711 (13.7 $\%)$

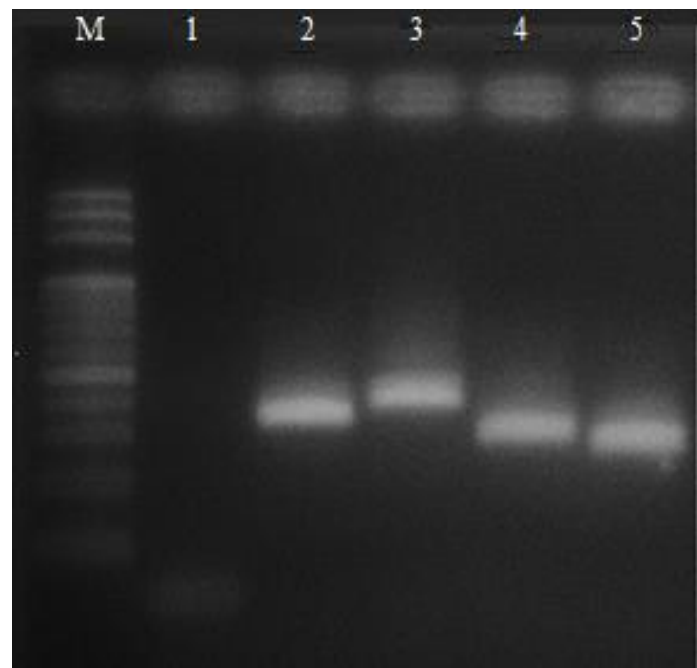

Fig. 1: An Ethidium Bromide-Stained Agarose Gel Electrophoresis Showingamplicons of X Region of the Spa Gene of S. Aureus Strains.Line M: Marker, Molecular Weight (100-1000 Bp) Line 1: Strain of Negative Control, Without Spa Gene Line 2: Strain of Positive Gene (ATCC 33591, S. Aureus), with Spa Gene Lines 3, 4, 5: Positive Samples with Spa Gene (200-600 Bp).

Table 1: Frequency of Resistance to Antimicrobial Agents among MRSA Isolates

\begin{tabular}{llll}
\hline Antibiotics & $\mathrm{S}[\mathrm{n}(\%)]$ & $\mathrm{I}[\mathrm{n}(\%)]$ & $\mathrm{R}[\mathrm{n}(\%)]$ \\
\hline $\mathrm{G}$ & $1(3.34)$ & $5(16.66)$ & $24(80)$ \\
$\mathrm{E}$ & $1(3.34)$ & $3(10)$ & $26(86.66)$ \\
$\mathrm{Ci}$ & $5(16.66)$ & $5(16.66)$ & $20(66.66)$ \\
\hline
\end{tabular}

$\mathrm{G}=$ Gentamycin, E= Erythromycin, $\mathrm{Ci}=$ Ciprofloxacin, $\mathrm{S}=$ Susceptible I= Intermediate, $\mathrm{R}=$ Resistance.

Table 2: Antibiotic Resistance Profiles and Molecular Typing of S.Aureus Isolates

\begin{tabular}{|c|c|c|c|c|c|c|}
\hline No. of isolates & Sample & Wards & Antibiotic resistance & Spa type & Repeats & mecA \\
\hline 1 & Trachea & ICU & $\mathrm{E}$ & $\mathrm{t} 030$ & $15-12-16-02-24-24$ & + \\
\hline 2 & Blood & Pediatric & E-Ci-Ge & $\mathrm{t} 030$ & $15-12-16-02-24-24$ & + \\
\hline 3 & Urine & Infection & $\mathrm{E}-\mathrm{Ci}$ & t030 & $15-12-16-02-24-24$ & + \\
\hline 4 & Trachea & Internal & $\mathrm{E}-\mathrm{Ge}$ & $\mathrm{t} 030$ & $15-12-16-02-24-24$ & + \\
\hline 5 & Nasal swab & PICU & $\mathrm{E}-\mathrm{Ci}$ & t030 & $15-12-16-02-24-24$ & + \\
\hline 6 & Tourniquet & Surgery & E-Ci-Ge & t711 & $04-21-17-34-24-34-22-25$ & - \\
\hline 7 & Patient bed & Surgery & E-Ci-Ge & t711 & $04-21-17-34-24-34-22-25$ & $\overline{+}$ \\
\hline 8 & Personnel & Surgery & $\mathrm{E}$ & t711 & $04-21-17-34-24-34-22-25$ & + \\
\hline 9 & Blood & $\mathrm{ICU}$ & E-Ci-Ge & t711 & $04-21-17-34-24-34-22-25$ & + \\
\hline 10 & CSF & Surgery & E-Ci-Ge & t002 & $26-23-17-34-17-20-17-12-17-16$ & + \\
\hline 11 & CSF & Pediatric & $\mathrm{Ge}$ & t002 & $26-23-17-34-17-20-17-12-17-16$ & + \\
\hline 12 & Patient bed & Pediatric & $\mathrm{E}$ & $\mathrm{t} 1556$ & $26-23-13-23-31-05-17-25-17-25-16-75-28$ & + \\
\hline 13 & Trolley & Pediatric & $\mathrm{E}-\mathrm{Ge}$ & $\mathrm{t} 1556$ & $26-23-13-23-31-05-17-25-17-25-16-75-28$ & + \\
\hline 14 & Urine & ICU & Sensitive to all & $\mathrm{t} 325$ & $07-12-21-17-34-13-34-34-33-34$ & _ \\
\hline 15 & Secretion & PICU & $\mathrm{Ge}$ & $\mathrm{t} 325$ & $07-12-21-17-34-13-34-34-33-34$ & + \\
\hline 16 & Urine & ICU & E-Ci-Ge & $\mathrm{t} 267$ & $07-23-12-21-17-34-34-34-33-34$ & + \\
\hline 17 & Abscess & Orthopedic & E-Ci-Ge & $\mathrm{t} 267$ & $07-23-12-21-17-34-34-34-33-34$ & + \\
\hline 18 & Blood & ICU & E-Ci-Ge & $\mathrm{t} 1358$ & $26-23-13-23-31-29-17-25-17-25-28$ & + \\
\hline 19 & Nasal swab & Operation & E-Ci-Ge & $\mathrm{t} 1358$ & $26-23-13-23-31-29-17-25-17-25-28$ & + \\
\hline
\end{tabular}




\begin{tabular}{llllll}
\hline 20 & Ventilator & ICU & E-Ge & t230 & $08-16-02-16-34$ \\
21 & Nasopharynx swab & ICU & E-Ci-Ge & t230 & $08-16-02-16-34$ \\
22 & Blood & Infant & E-Ge & t2422 & $07-23-12-34-38-12-12-23-02-12-23$ \\
23 & Urine & Cardiac & E-Ci-Ge & t969 & $15-12-02-24-24$ \\
24 & Urine & Internal & E-Ci-Ge & t & $07-12-21-17-34-34-34-33-34$ \\
25 & Urine & Internal & E-Ci-Ge & t037 & $15-12-16-02-25-17-24$ \\
26 & Patient bed & Emergency & E-Ci-Ge & t300 & $01-12-16-16-02-16-02-25-24-24$ \\
27 & Nasal swab & ICU & E-Ci-Ge & t180 & $09-02-16-34-34-34-17-34-16-34$ \\
28 & Blood & Emergency & E-Ci-Ge & t5598 & $08-16-34-24-34-17$ \\
29 & Incubator & Surgery & E-Ci-Ge & t044 & $07-23-12-34-34-33-34$ \\
30 & CSF & Internal & E-Ci-Ge & NT \\
\hline
\end{tabular}

The increasing incidence of infections caused by methicillinresistant Staphylococcus aureus (MRSA), prevention of infection and spread of bacteria in hospitals to focus detection is essential. MRSA isolates to have appeared and become the most common cause of nosocomial infections in Iran [16]. In this study, the prevalence rate of MRSA was $93.33 \%$. High rate of MRSA (Hospital-acquired/associated MRSA infections) are reported in East Asia, especially in Sri Lanka (86.5\%), South Korea (77.6\%), Vietnam (74.1\%), Taiwan (65.0\%), Thailand (57.0\%) and Hong Kong (56.8\%). In 2010, 26 European countries reported MRSA rate from $0 \%$ in Denmark, Estonia, The Netherlands, Norway and Sweden to $55.6 \%$ in Malta [17], [18]. The difference at the resistance rate of S.aureus to antibiotics in different countries or hospitals is due to the differences in policies patient treatment or hospital health control. Different methods of cultivation and isolation, antibiotic susceptibility assay, geographical differences and the population of the study also cause variation in previous findings. In addition, inappropriate prescription antibiotics in nonbacterial infections, non-full course of treatment as well as easy availability of antibiotics help to emergence and spread of multidrug resistance strains[19].We used spa-typing since it has several advantages in terms of speed, ease of use, ease of interpretation and database creation for MRSA strain typing[20]. The The most frequently encountered MRSA spa type among our strains was t030, probably the most widespread MRSA in Iranian hospitals [21]. Studies have shown that multidrug-resistant strains Spa type t030 and it is becoming resistant to many antibiotics [22], [23]. however, Countries of origin spa-type t030 has been shown in , Austria, Bulgaria, China, Croatia, Cyprus, Czech Republic, Denmark, France, Germany, Iran, Lebanon, Macedonia, Netherlands, Norway, Romania, South Africa, Spain, Sweden, Switzerland, Turkey. Overall, the present study suggests a recirculation movement of S. aureus strains between the patients, personnel and hospital environment in a hospital .The spread of antimicrobial to MRSA clones with specific genotypes within patients and personnel is a particular cause of concern and could have important implications for the implementation of effective infection control strategies and measures. In the current study, spa typing method showed $96.66 \%$ type ability we suggest the use of additional typing methods such as PFGE, BURP and MLST to overcome the limitation of a single locus-based molecular typing (spa typing).

\section{Conclusions}

This study showed a high rate of methicillin resistance among isolates S. aureus. Therefore, the correct selection of appropriate antibiotics to treat infections caused by S. aureus and prevention of resistance to antibiotics effective against most strains is important. Use of spa typing in this study might be a used as appropriate tool with other molecular methods in classification of this microorganism. Thus, the continuous review of the pattern of resistance and genetic characteristics of these organisms areimportant in order to controlling infections acquired from the hospital and community.

\section{Acknowledgment}

This is part of Hadi Mohammadi Talvar (Microbiology M.Sc. student) thesis. The authors wish to extend their gratitude to the Research Deputy of Kurdistan University of Medical Sciences for financial support.

\section{References}

[1] Shopsin, B. and B.N. Kreiswirth, Molecular epidemiology of methicillin-resistant Staphylococcus aureus. Emerging infectious $\begin{array}{llll}\text { diseases, } & \text { 2001. } & 7(2): & \text { p. }\end{array}$ https://doi.org/10.3201/eid0702.010236.

[2] Church, D.L., et al., Comparison of automated repetitive-sequencebased polymerase chain reaction and $<i>$ spa $</ i>$ typing versus pulsed-field gel electrophoresis for molecular typing of methicillinresistant $<\mathrm{i}>$ Staphylococcus aureus $</ \mathrm{i}>$. Diagnostic microbiology and infectious disease, 2011. 69(1): p. 30-37. https://doi.org/10.1016/j.diagmicrobio.2010.09.010.

[3] Deurenberg, R.H. and E.E. Stobberingh, The evolution of $<$ i $>$ Staphylococcus aureus $</ \mathrm{i}>$. Infection, genetics and evolution, 2008. 8(6): p. 747-763. https://doi.org/10.1016/j.meegid.2008.07.007.

[4] Vainio, A., Molecular methods for the epidemiological analysis of methicillin-resistant Staphylococcus aureus (MRSA) and Streptococcus pneumoniae. 2012.

[5] Hallin, M., A.W. Friedrich, and M.J. Struelens, spa typing for epidemiological surveillance of Staphylococcus aureus, in Molecular Epidemiology of Microorganisms. 2009, Springer. p. 189-202.

[6] Struelens, M., et al., Laboratory tools and strategies for methicillinresistant Staphylococcus aureus screening, surveillance and typing: state of the art and unmet needs. Clinical microbiology and infection, 2009. 15(2): p. 112-119. https://doi.org/10.1111/j.14690691.2009.02698.x.

[7] Frenay, H., et al., Molecular typing of methicillinresistantStaphylococcus aureus on the basis of protein A gene polymorphism. European Journal of Clinical Microbiology and Infectious Diseases, $1996 . \quad 15(1)$ : p. 60-64 https://doi.org/10.1007/BF01586186.

[8] Frenay, H., et al., Discrimination of epidemic and nonepidemic methicillin-resistant Staphylococcus aureus strains on the basis of protein A gene polymorphism. Journal of clinical microbiology, 1994. 32(3): p. 846-847.

[9] Friedrich, A., et al., SeqNet. org: a European laboratory network for sequence-based typing of microbial pathogens. Euro surveillance: bulletin europeen sur les maladies transmissibles= European communicable disease bulletin, 2005. 11(1): p. E060112. 4-E060112. 4.

[10] Stefani, S., et al., Meticillin-resistant $<$ i> Staphylococcus aureus </i > (MRSA): global epidemiology and harmonisation of typing methods. International journal of antimicrobial agents, 2012. 39(4): p. 273-282. https://doi.org/10.1016/j.ijantimicag.2011.09.030.

[11] Mahon, C., G. Manuselis, and D. Lehman, Textbook of Diagnostic Microbiology, Saunders. 2000, ISBN 0-7216-7917-X.

[12] Wang, S.-C., et al., Distribution of superantigenic toxin genes in< i $>$ Staphylococcus aureus $</ i>$ isolates from milk samples of bovine subclinical mastitis cases in two major diary production regions of China. Veterinary microbiology, 2009. 137(3): p. 276-281. https://doi.org/10.1016/j.vetmic.2009.01.007.

[13] Maniatis, T., E.F. Fritsch, and J. Sambrook, Molecular cloning: a laboratory manual. Vol. 545. 1982: Cold Spring Harbor Laboratory Cold Spring Harbor, NY.

[14] Cockerill, F.R., Performance standards for antimicrobial susceptibility testing: twenty-first informational supplement. 2011: Clinical and Laboratory Standards Institute (CLSI). 
[15] Stegger, M., et al., Rapid detection, differentiation and typing of methicillin-resistant Staphylococcus aureus harbouring either mecA or the new mecA homologue mecALGA251. Clinical Microbiology and Infection, 2012. 18(4): p. 395-400 https://doi.org/10.1111/j.1469-0691.2011.03715.x.

[16] Fatholahzadeh, B., et al., Characterisation of genes encoding aminoglycoside-modifying enzymes among meticillin-resistant $<i>$ Staphylococcus aureus $</ \mathrm{i}>$ isolated from two hospitals in Tehran, Iran. International journal of antimicrobial agents, 2009. 33(3): p. 264-265. https://doi.org/10.1016/j.ijantimicag.2008.09.018.

[17] Song, J.-H., et al., Spread of methicillin-resistant Staphylococcus aureus between the community and the hospitals in Asian countries: an ANSORP study. Journal of antimicrobial chemotherapy, 2011. 66(5): p. 1061-1069. https://doi.org/10.1093/jac/dkr024.

[18] Borg, M., L. Camilleri, and B. Waisfisz, Understanding the epidemiology of MRSA in Europe: do we need to think outside the box? Journal of Hospital Infection, 2012. 81(4): p. 251-256. https://doi.org/10.1016/j.jhin.2012.05.001.

[19] Vahdani, P., et al., Antibiotic resistant patterns in MRSA isolates from patients admitted in ICU and infectious ward. Tanaffos, 2004 3(11): p. 37-44.

[20] Alp, E., et al., MRSA genotypes in Turkey: persistence over 10 years of a single clone of ST239. Journal of Infection, 2009. 58(6): p. 433-438. https://doi.org/10.1016/j.jinf.2009.04.006.

[21] Mirzaii, M., et al., Molecular investigation of $<\mathrm{i}>$ Staphylococcus aureus $\langle/ i>$ isolated from the patients, personnel, air and environment of an ICU in a hospital in Tehran. Journal of infection and public health, 2014.

[22] He, W., et al., Population structure and characterisation of $<\mathrm{i}>$ Staphylococcus aureus $</ \mathrm{i}>$ from bacteraemia at multiple hospitals in China: association between antimicrobial resistance, toxin genes and genotypes. International journal of antimicrobial agents, 2013. 42(3): p. 211-219. https://doi.org/10.1016/j.ijantimicag.2013.04.031.

[23] Xiao, Y.-H., et al., Epidemiology and characteristics of antimicrobial resistance in China. Drug resistance updates, 2011. 14(4): p. 236-250. https://doi.org/10.1016/j.drup.2011.07.001. 